Kohl: a Journal for Body and Gender Research

Vol. 2, No. 1 (Summer 2016)

\title{
Compulsory Military Service and Gender in Druze Communities under Occupation
}

\author{
Maisan Hamdan
}


"Whom did the Druze betray? Her state or her religion?"

"We need to expel her from the country."

"Go live in Gaza or in Syria."

"We don't have women who talk about politics."

"She is destroying the future of the youth."

Newspapers articles and the children of my village both targeted me with these statements. Life under occupation has forced me to choose between two options: either to deny reality and to deal with the presence of the occupation as natural and legitimate, or to go towards political activism, both in word and in action.

I chose the latter. I started my political activism in 2007, when I was still in high school. The students and the administrative staff described me as a terrorist, and I was subsequently dropped out of media studies classes at Emek Yizrael College because of my political background.

Later, in 2010, I founded a group against conscription with a group of male and female activists, which later became an organized movement that we named "Refuse, your People will protect you," and we launched it formally in 2014. All of us, men and women, came from an environment repressive of difference, so we decided to uphold to feminist values in the movement we were creating, thus breaking all the regulations that were part of our upbringing.

Feminism seemed important to a movement that refuses compulsory military service, because it challenges the gender discrimination rooted in it. Conscription entrenches the inherited social concepts on gender. Our affect with these concepts starts at the moment of our birth, as manhood was injected in the boys' mentalities in different ways. For example, social pressure asks them to deny their feelings, to act in a way that highlights their physical strength, and to prove themselves by controlling others, or competing with them. Exerting control, power, and violence over others is perceived to be one of the signs of manhood. This socialization undermines everyone's dignity.

Boys and men are usually brutally treated in preparation for military service. War itself is gender-based violence, and it is also against men, as men and boys are forced to fight and kill as required by conscription.

On the other hand, girls are usually socially driven to deny their culture, to be good listeners, to be polite and obedient. They also have to prove themselves to be effective by putting the needs of others first. Passivity and acceptance of injustice might be regarded as markers of femininity. Such social upbringing undermines human dignity and promotes the creation of victims.

Returning to gender, we find out that it is a social form of the ideas that define the roles, the belief systems, the attitudes, the images, the values, and the expectations from men and women. It contributes significantly to determining power relations, not only between men and women, but also between groups, so we end up with an oppressor and an oppressed, leading to a lot of social problems. And this necessarily is a source of 
the production of classism, and the lack of equal rights and duties in society's perception of gender, at work, in politics and, therefore, in the persistence of injustice.

Different cultures have different ideas about gender, about what acts are appropriate for men and women, and what they should conform to. The concept of gender is not only different from culture to culture, but it could change over time and through different ages within the same culture, or it can change during an emergency and with the existence of a crisis.

Many cultures treat men's experiences and concepts as natural, and take the masculine heterosexual behavior as standard. For example, the exercise of power, and its publicizing in particular, is perceived as a manly behavior. In most cultures, it is assumed that the man is the leader of the family and the society, while women are seen as a subsidiary and supportive.

This is reflected in many of the prevailing sayings: for example, "behind every great man, there is a woman," so no matter how great the man is, the woman remains behind him. This might entail the assumption that women and girls do not have much of a say in decisions concerning their lives. Rather, they have guardians, and this could also mean that men who do not follow the traditional roles face public criticism. Yet, because gender is a socially constructed idea, it is possible to defy it and to change the oppressive notions about male and female roles. This is what we call Gender Justice.

Compulsory military service in Israel embodies one example of gender discrimination. If not deployed in battle fields, men serve a period of three years in the Israeli army, while women serve a lesser amount of time, i.e. two years. Women's jobs are usually limited to supporting positions. However, since 2000, women are allowed to serve in combat units if they wish to do so. In that case, they would serve for three years, like the men. It is not the case with Druze women, as they are prevented from performing the service, out of respect for the traditions of the community.

In Israel, conscription encompasses all citizens, whether Palestinians or Jews, above the age of eighteen, according to the Israeli law. This is the case since the founding of the Israeli army in the May 26, 1948 and until now. Some citizens were exceptionally exempted later for several reasons.

Despite the historical failure of the Israeli efforts to recruit Palestinian, Israel continues these attempts, employing coercive laws to its service, and/or pretending to follow non-existing laws. For example, the exemption of the Palestinians of 1948 of all sects from Israeli military service is not codified under Israeli law. In fact, they have not undergone the exams or registration process in the army since the founding of the Israeli state on the Palestinian land, and were exempted in 1949.

In 1954, the Israeli Security Bureau attempted to recruit Palestinians to military service, to no avail, since this attempt was met with a severe Palestinian resistance. In 1956, young Palestinian Druze from non-religious backgrounds were forcefully recruited. Two years later, young Circassians were forcefully recruited as well, with the exemption of women from both communities. Israeli law also enforced sanctions on anyone who 
tries to avoid the military service; Article $46 \mathrm{~A}$ of the Israeli Security Service Law stipulates that "anyone who does not complete his term of service imposed by law, will serve a two-year sentence." Article 46 B states that "those who intentionally evade the service will be incarcerated for a maximum of five years."

Military service is imposed upon the Palestinian Druze, knowing that international law and the rights of minorities prevent their conscription wherever they are. Druze peasants have been removed from their land because of their resistance, and thus kept away from their primary source of living. Also, many of those who have evaded the military service have been prosecuted.

The first and most influential factor in the subordination of the Druze to the conscription is land. The Druze resisted the military service for several years, and many young people fled to the fields closest to their hometowns, some hiding there for days and even weeks. As a result, the occupation authorities promised the Druze not to confiscate their land. In exchange for their acceptance to serve in the army, they would be allowed to exercise their natural right in agriculture. But despite the Israeli authority's use of the language of rights and duties with the Druze, and despite their policy that allocates agricultural land for the Druze, they have confiscated what exceeds 80 percent of Palestinians Druze land, and demolished houses in several villages sous-pretext the lack of a permit. ${ }^{2}$

Later, other factors have led to the Druze youth accepting conscription without hesitation, including the provision of a piece of land for construction for each young man immediately after completion of the service, and the provision of budgets for the development of infrastructure in each village. From a professional point of view, one does not need a university or even a school degree to work in security. Hence, a young man is guaranteed a job without needing education.

According to the Israeli narrative, the elders of Palestinian Druze sheikhs and scientists (16 out of the total number of Palestinian Druze in the occupied territories at the time) went to the occupation authorities asking to serve in the army, and intended to be a part of it, and signed an agreement to confirm this. But, there is not any document indicating the validity of the claim, and this was confirmed by Professor Qais Ferro in his research. ${ }^{3}$

But the mere trust in such a tale and its adoption raise many questions regarding the ease of the acceptance of this idea. Regardless of the invalidity of this Israeli version, the acceptance of it is euphemism for the attachment to the fate of generations to come to a pronouncement of male elders who had no right to take such a decision.

1 The articles have been translated from Israeli security's military service legislations.

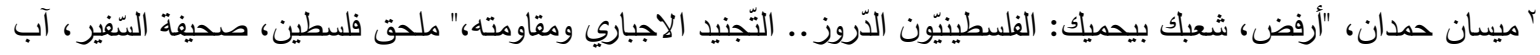

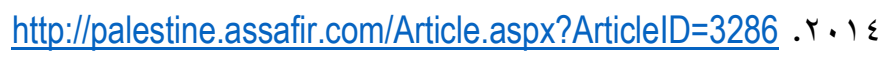

3 lbid. 
Given the strength of the religious establishment in Arab societies in general, the Druze community was hacked and influenced through it. The Israeli establishment has used the strategy of considering Jewishness to be both a religion and an ethnicity in order to create a special nation for the Druze, and subsequently integrate them in their warfare institution. So Israel recognized the Druze as a national minority in 1957, despite the movement refusing conscription at the time.

The occupation authorities have established the idea of a blood alliance in the mind of every young Druze. Accordingly, they claimed that the Druze are equal in rights and duties with the Jews in the state. Hence, a large portion of the Druze no longer recognized their Palestinian identity or their belonging to the wider culture of the region. After fifty-nine-years since the imposition of the compulsory military service, some Druze families gear their children towards the fields of security or the police, thus contributing to the preservation of a patriarchal misogynistic society: the young Druze man working in the security field enjoys an increase in pay when he marries. By virtue of his work, he may be absent for many consecutive weeks, thus forcing the wife to maintain the traditional caregiving role for the house and the children, not to mention the impossibility of working outside of the home, or reaching effective professional positions. In the long term, conscription reproduces the patriarchal dynamic and maintains a traditional society.

Gradually, the Israeli establishment has continued to take measures to consolidate the idea of the special nationalism of the Druze, in several stages:

In 1976, the Israeli establishment separated local councils, located in villages called the "Druze villages," from those in the rest of the Arab villages. In the same year, the school curricula were separated as well and tailored for schools located in the "Druze villages" a special curriculum with an annexation of selected materials, to contribute to the manipulation of history and the facts. The covers of books read: "Arabic language for Druze schools," "Hebrew language for Druze schools," "Mathematics for Druze schools," and so forth. ${ }^{4}$

Today, it is common practice to see one or two young Druze soldiers roaming the school daily to provide sufficient information to male students, highlighting strands of power and control, and stressing their social role. They reinforce the notion the next phase after high school is necessarily joining the ranks of the occupation army. While this future looks bleak, there is no mention whatsoever of the future of the female students.

In addition to that, in the context of education, some junior high schools were transformed into military schools to which the male students go wearing military uniforms, demonstrating the added power of the military uniform for male students in front of their female colleagues.

4 lbid. 
Compulsory military service is a tool to suppress freedoms on several levels, whether by emphasizing the added-value of the man, or by linking it to the concept of power and control, or through its reflection in the incidents of violence against women or within the family.

For instance, after the acceptance of conscription in the occupation army as a reality in the Palestinian Druze community, the young conscript came to be seen as the strongest and the worthiest of respect. So for example, when he climbs into a bus, people rush to make room for him to sit. Similarly, boys are constantly asked during their childhoods: "Who wants to grow up tomorrow and become a soldier and carry a weapon?" They are taken to exhibitions of arms to embrace and consolidate a singular and clear future for everyone: the young soldier is the head of the community.

As for linking conscription to incidents of violence in the family, and against women in particular, repeated murders of women were carried through the use of the weapon of the military father/spouse/son, as it remains in his possession during his stay in the house.

Conscription is directly linked to gender. Its drawbacks are reflected on the community and take on class dimensions. The relationship of compulsory military service with gender is entrenched by the day in the mentality of younger generations, and it taints our lives with injustice and fraud. So if we are to apply gender justice and free ourselves from the traditional images and inherited stereotypes, it is necessary to liberate ourselves from conscription first. 